

open research

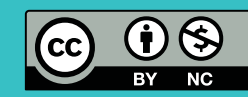

\section{Stratification of eosinophilic asthma patients treated with reslizumab and GINA Step 4 or 5 therapy}

\author{
Guy Brusselle ${ }^{1,2}$, Janice Canvin $\mathbb{1 0}^{3}$, Sivan Weiss ${ }^{4}$, Shawn X. Sun ${ }^{5}$ and \\ Roland Buhl ${ }^{6}$
}

Affiliations: ${ }^{1}$ Dept of Respiratory Medicine, Ghent University Hospital, Ghent, Belgium. ${ }^{2}$ Depts of Respiratory Medicine and Epidemiology, Erasmus Medical Center, Rotterdam, the Netherlands. ${ }^{3}$ Teva Pharmaceuticals, Amsterdam, the Netherlands. ${ }^{4}$ Teva Pharmaceuticals, Netanya, Israel. ${ }^{5}$ Teva Pharmaceuticals, Frazer, PA, USA. ${ }^{6}$ Pulmonary Dept, University Hospital, Johannes Gutenberg-University, Mainz, Germany.

Correspondence: Guy Brusselle, Department of Respiratory Medicine, Ghent University Hospital, De Pintelaan 185, B-9000 Ghent, Belgium. E-mail: Guy.Brusselleduzgent.be

ABSTRACT Reslizumab, an anti-interleukin-5 monoclonal antibody, significantly reduces exacerbation frequency and improves lung function, asthma control and quality of life in adults with severe eosinophilic asthma, as demonstrated in Phase III studies.

This secondary analysis assessed reslizumab's efficacy in patients receiving baseline treatment per Global Initiative for Asthma (GINA) Step 4 and Step 5 guidelines.

Pooled data from duplicate, Phase III, reslizumab versus placebo studies in patients with severe eosinophilic asthma (blood eosinophils $\geqslant 400$ cells $\mu \mathrm{L}^{-1}$ ) were stratified by baseline therapy. Efficacy assessments were exacerbation rates and changes from baseline forced expiratory volume in $1 \mathrm{~s}(\mathrm{FEV} 1)$ and patient-reported outcomes.

Of 953 patients, 69\% $(n=657)$ and 11\% $(n=106)$ were receiving Step 4 and Step 5 therapy, respectively. Compared with placebo, reslizumab reduced exacerbation rates by 53\% (95\% CI 0.36-0.62) and 72\% (95\% CI 0.15-0.52), in Step 4 and Step 5 groups respectively. By study end, reslizumab increased FEV1 in Step 4 and Step 5 groups by $103 \mathrm{~mL}(95 \%$ CI 52-154 mL) and $237 \mathrm{~mL}$ (95\% CI 68-407 mL), respectively. Reslizumab also improved patient-reported outcomes compared with placebo in both groups.

Reslizumab reduces exacerbation rates and improves lung function and patient-reported outcomes in patients with eosinophilic asthma receiving therapy per Steps 4 and 5 of the GINA guidelines.

@ERSpublications

Subanalyses of Phase III data: severe eosinophilic asthma patients benefit from reslizumab plus GINA 4/5 therapy http://ow.ly/6zJU30e8T2b

Cite this article as: Brusselle G, Canvin J, Weiss S, et al. Stratification of eosinophilic asthma patients treated with reslizumab and GINA Step 4 or 5 therapy. ERJ Open Res 2017; 3: 00004-2017 [https://doi.org/10.1183/23120541.00004-2017].

This article has supplementary material available from openres.ersjournals.com Received: Jan 062017 | Accepted after revision: July 142017

Support statement: This research was funded by Teva Branded Pharmaceutical Products R\&D. Funding information for this article has been deposited with the Crossref Funder Registry.

Conflict of interest: Disclosures can be found alongside this article at openres.ersjournals.com

Copyright $\odot$ ERS 2017. This article is open access and distributed under the terms of the Creative Commons Attribution Non-Commercial Licence 4.0. 


\section{Introduction}

Worldwide, there are over 300 million people with a diagnosis of asthma [1], and this number is predicted to increase to at least 400 million by the year 2025 [2]. Despite the use of inhaled corticosteroids (ICS) combined with other drugs as standard of care [3], many patients have asthma that requires either treatment with high-dose ICS plus a second controller, or the addition of systemic corticosteroids to gain control; these patients are considered to have severe asthma [4].

Patients who have severe asthma with an eosinophilic phenotype, as characterised by elevated blood and/ or sputum eosinophil counts, have increased exacerbation rates, impaired lung function, poorer symptom control and lower quality of life (QoL) compared with patients with non-eosinophilic asthma [5]. Blood eosinophil counts $\geqslant 400$ cells $\mu \mathrm{L}^{-1}$ have a proven association with increased frequency and severity of clinical asthma exacerbations (CAEs) and poor asthma control [6]. This has led to the development of novel therapies that target the molecular regulators of eosinophil function in asthma pathophysiology.

Interleukin-5 (IL-5) is the key regulator of eosinophil maturation, mobilisation from the bone marrow and recruitment to sites of inflammation [7, 8]. Reslizumab, an intravenously administered humanised anti-IL-5 monoclonal antibody, has been developed to inhibit the pro-inflammatory action of IL-5 on eosinophils [9-11].

Reslizumab has been approved in the USA, the EU and Canada as add-on maintenance treatment of patients aged 18 years and older with severe eosinophilic asthma [12-14]. Owing to insufficient clinical data in patients aged $<18$ years, reslizumab is not currently approved for use in children (aged $\leqslant 11$ years) or adolescent patients (aged 12-17 years) [12, 13].

The efficacy and safety of reslizumab versus placebo have been demonstrated in duplicate placebo-controlled Phase III studies, in patients with inadequately controlled asthma and elevated blood eosinophils $\left(\geqslant 400\right.$ cells $\left.\mu \mathrm{L}^{-1}\right)$ who were aged $12-75$ years [9]. For inclusion in these studies, eligible patients were receiving at least a medium dose of ICS $\left(\geqslant 440 \mu \mathrm{g} \cdot \mathrm{day}^{-1}\right.$ fluticasone proprionate, or equivalent) with or without another controller drug (long-acting $\beta_{2}$ agonist (LABA), oral corticosteroids (OCS), leukotriene receptor inhibitors (LTRI), lipoxygenase inhibitors or cromolyn sodium) [9], representing Step 3-5 treatment according to the Global Initiative for Asthma (GINA) guidelines [15].

Data from both studies demonstrated that, compared with placebo, reslizumab significantly reduced the annual frequency of asthma exacerbations by $54 \%$ (pooled data, $\mathrm{p}<0.0001$ ), and reduced the occurrence of CAEs requiring at least 3 days of OCS use by $57 \%(\mathrm{p}<0.0001)$ with a safety profile comparable to that of placebo [9]. Reslizumab treatment also rapidly improved lung function, with patients showing significant improvements in forced expiratory volume in $1 \mathrm{~s}$ (FEV1) at the first on-study assessment (week 4) $(\mathrm{p}<0.05)$ that were sustained throughout the study [9]. Patient-reported outcomes (Asthma Control Questionnaire-7 (ACQ-7) and Asthma Quality of Life Questionnaire (AQLQ) scores) were also significantly improved from first on-study assessment throughout the study, demonstrating increased control of symptoms and improved QoL [9].

We performed a secondary analysis of the Phase III data to determine the efficacy of reslizumab as add-on therapy in patients receiving asthma treatment per Step 4 and Step 5 of the GINA guidelines at baseline.

\section{Patients and methods}

Both studies included in this analysis were Phase III, international, randomised, double-blind, parallel-group, placebo-controlled studies to assess the efficacy and safety of reslizumab $\left(3 \mathrm{mg} \cdot \mathrm{kg}^{-1}\right.$ i.v. every 4 weeks) compared with placebo. These studies have been published previously [9].

In brief, both studies enrolled patients with inadequately controlled asthma (ACQ-7 score of $\geqslant 1.5$ ) [16]. Current smokers (within the previous 6 months) were excluded. Patients were aged 12-75 years with eosinophilic asthma, defined as at least one blood eosinophil count of $\geqslant 400$ cells $\mu \mathrm{L}^{-1}$ during a $2-4$-week screening period.

Eligible patients received medium-to-high dose ICS at baseline (fluticasone propionate $\geqslant 440 \mu \mathrm{g} \cdot \mathrm{day}^{-1}$, or equivalent) with or without another controller (including OCS). Patients continued to use their GINA Step 4 or Step 5 asthma treatment, including any add-on therapy, throughout the study. The use of omalizumab or other biologic therapy was not permitted.

Eligible patients were also required to have had at least one exacerbation requiring the use of systemic corticosteroids for $\geqslant 3$ days within the 12 months before screening and have an FEV1 reversibility of $\geqslant 12 \%$ with salbutamol.

Patients were randomised 1:1 to receive either reslizumab $3 \mathrm{mg} \cdot \mathrm{kg}^{-1}$ i.v. every 4 weeks for 13 doses, or matching placebo. 
The primary endpoint of both studies was the annual CAE frequency and secondary endpoints included change from baseline FEV1, ACQ-7 score and AQLQ score [9].

Both studies were conducted according to Good Clinical Practice guidelines, the Declaration of Helsinki and local regulatory requirements. Relevant health authorities and local ethics committees or institutional review boards approved the study protocols, and all patients provided written informed consent.

\section{Statistical analyses}

Patients were stratified into GINA Step 4 and Step 5 groups based on their baseline medications at the time they were randomised to treatment arms in the duplicate studies. Patients comprising the Step 4 group were defined as receiving $\geqslant 2$ controllers (medium-to-high dose ICS plus a LABA or LTRI) plus as-needed reliever medication; the Step 5 group was defined as receiving add-on treatment with OCS. Patients with insufficient information on their baseline medication were excluded from these analyses to ensure the integrity of the Step 4 and Step 5 subsets.

All efficacy endpoints were assessed in the intent-to-treat population (all randomised patients aged 12-75 years). CAE frequency was analysed using a negative binomial regression model as previously described [9]. Rate ratios (RRs) versus placebo (with 95\% CIs) were estimated using the same model.

The secondary endpoints were analysed using mixed models for repeated measures with treatment, study visit, treatment by visit interaction and stratification factors as fixed factors, and covariates for baseline value and patient as a random effect. For pulmonary function endpoints, the model also included sex and height.

The proportions of patients achieving a clinically meaningful improvement in AQLQ or ACQ-7 scores (a $\geqslant 0.5$-point change in score) $[17,18]$ were analysed using a stratified Cochran-Mantel-Haenszel test. Data were pooled from both studies to perform subgroup analyses for primary and secondary endpoints.

Further sub-analyses were performed based on the types and doses of medications received at baseline. In the GINA Step 4 group, only 11 patients were receiving ICS and LTRI at baseline (seven in the placebo group and four in the reslizumab group); because of the limited data available for this subgroup, meaningful statistics for CAEs, FEV1 and patient-reported outcomes could not be calculated.

\section{Results}

\section{Patient population}

Patient demographics and clinical characteristics are summarised in table 1. In general, baseline demographics were well balanced across placebo and reslizumab groups within the Step 4 and Step 5 populations. At baseline, more patients were receiving Step 4 treatment $(n=657)$ than Step 5 treatment $(n=106)$. Patients in the Step 4 group were slightly younger than those in the Step 5 group: median ages were 48 and 52 years, respectively. Only 19 patients aged $12-17$ years were receiving Step 4 (placebo $n=7$; reslizumab $\mathrm{n}=11$ ) or Step 5 therapy (placebo $\mathrm{n}=1$ ) at baseline. In both Step 4 and Step 5 groups, a greater proportion of patients were female: $63 \%$ and $58 \%$, respectively. Compared with patients receiving Step 4 treatment, a higher proportion of Step 5 patients were of white race (92\% versus $75 \%$ ).

In line with more severe disease in patients receiving GINA Step 5 treatment, baseline lung function and patient-reported outcome data differed between the Step 4 and Step 5 populations. FEV1 values and AQLQ scores were lower in the Step 5 group compared with the Step 4 group, whereas ACQ-7 scores were higher in the Step 5 group, implying worse asthma control. In the Step 5 group, patients received oral corticosteroids at a mean $\pm \mathrm{SD}$ dose (prednisone or equivalent) of $8.2 \pm 7.65 \mathrm{mg}$ in the placebo arm and $7.1 \pm 2.84 \mathrm{mg}$ in the reslizumab arm.

\section{Clinical asthma exacerbations}

Compared with placebo, reslizumab add-on therapy reduced the adjusted CAE rate in Step 4 and Step 5 populations by 53\% (RR 0.47; 95\% CI 0.36-0.62) and 72\% (RR 0.28; 95\% CI 0.15-0.52), respectively (fig. 1a).

An analysis of the Step 4 subpopulation by baseline medication demonstrated that reslizumab reduced CAE rates by $61 \%$ (RR 0.39; 95\% CI $0.27-0.58$ ) and $43 \%$ (RR 0.57 ; 95\% CI 0.39-0.86) in patients receiving medium-dose and high-dose ICS/LABA at baseline, respectively. This difference may be due to the higher efficacy of high-dose ICS/LABA in prevention of exacerbations.

During the study, exacerbations requiring intervention with either systemic corticosteroids, hospitalisation or a visit to the emergency room occurred in a total of 272 patients (174 in the placebo group and 98 in the reslizumab group). Compared with placebo, reslizumab significantly reduced the rate of CAE requiring OCS by $56 \%$ in the Step 4 group (RR $0.44 ; 95 \%$ CI $0.32-0.60$ ) and by $72 \%$ in the Step 5 group (RR 0.28 ; 95\% CI 0.14-0.55) (fig. 1b). 
TABLE 1 Baseline demographics and characteristics for randomised patients: Global Initiative for Asthma (GINA) Step 4 and GINA Step 5

\begin{tabular}{|c|c|c|c|c|c|c|}
\hline & \multicolumn{3}{|c|}{ GINA Step 4} & \multicolumn{3}{|c|}{ GINA Step 5} \\
\hline & Placebo & Reslizumab & Total & Placebo & Reslizumab & Total \\
\hline Patients n & 322 & 335 & 657 & 58 & 48 & 106 \\
\hline Male & 107 (33) & $133(40)$ & 240 (37) & $23(40)$ & $22(46)$ & $45(42)$ \\
\hline \multicolumn{7}{|l|}{ Race } \\
\hline Asian & $46(14)$ & $46(14)$ & $92(14)$ & 2 (3) & 4 (8) & $6(6)$ \\
\hline Other & $22(7)$ & $27(8)$ & $49(7)$ & 0 & 0 & 0 \\
\hline BMI kg $\cdot \mathrm{m}^{-2}$, mean $\pm \mathrm{sD}$ & $27.5 \pm 5.62$ & $27.3 \pm 5.68$ & $27.4 \pm 5.65$ & $26.9 \pm 5.23$ & $27.5 \pm 5.92$ & $27.2 \pm 5.54$ \\
\hline Patients with atopic history & $211(66)$ & $212(63)$ & $423(64)$ & $37(64)$ & $27(56)$ & $64(60)$ \\
\hline Patients with seasonal allergies" & $103(64)$ & $89(52)$ & $192(58)$ & 14 (35) & $8(33)$ & $22(34)$ \\
\hline $\begin{array}{l}\text { CAEs in the } 12 \text { months prior to } \\
\text { enrolment } n \text {, mean } \pm \text { SE }\end{array}$ & $1.8 \pm 0.08$ & $1.8 \pm 0.08$ & $1.8 \pm 0.06$ & $3.4 \pm 0.46$ & $2.6 \pm 0.37$ & $3.0 \pm 0.30$ \\
\hline ACQ-7 score & $\begin{array}{c}2.571 \\
(0.143-5.429)\end{array}$ & $\begin{array}{c}2.429 \\
(0.429-5.000)\end{array}$ & - & $\begin{array}{c}3.071 \\
(1.143-5.571)\end{array}$ & $\begin{array}{c}3.214 \\
(1.286-5.286)\end{array}$ & - \\
\hline AQLQ score & $\begin{array}{c}4.156 \\
(1.406-7.000)\end{array}$ & $\begin{array}{c}4.469 \\
(1.719-6.969)\end{array}$ & - & $\begin{array}{c}3.906 \\
(1.656-6.125)\end{array}$ & $\begin{array}{c}3.797 \\
(1.750-6.250)\end{array}$ & - \\
\hline
\end{tabular}

Data are presented as $\mathrm{n}(\%)$ or median (range), unless otherwise stated. BMI: body mass index; CAE: clinical asthma exacerbation; OCS: oral corticosteroids; IVRS: interactive voice response system; FEV1: forced expiratory volume in $1 \mathrm{~s}$; ACQ-7: asthma control questionnaire-7; AQLQ: asthma quality of life questionnaire. " : Data for patients with seasonal allergies only available for Study 2.

Because of the low number of patients aged 12-17 years in the pivotal studies (Step 4: placebo $\mathrm{n}=7$, reslizumab $\mathrm{n}=11$; Step 5: placebo $\mathrm{n}=1$ ), the effects of reslizumab treatment on healthcare resource utilisation, hospitalisation or a visit to the emergency room due to a CAE were assessed only in adult patients (aged $\geqslant 18$ years). Reslizumab reduced the rate of CAE-related hospitalisations and visits to the emergency room by $50 \%$ (95\% CI $0.25-0.97$ ) compared with placebo (fig. 1c). This effect was greater in patients who had experienced $\geqslant 2$ exacerbations in the previous year, with reslizumab reducing the exacerbation-related hospitalisation/emergency room visit rate by $72 \%$ (95\% CI $0.11-0.72$ ) (fig. 1c).

\section{Lung function}

In GINA Step 4 and Step 5 groups, reslizumab increased FEV1 compared with placebo at weeks 16 and 52 (fig. 2a). At week 16, reslizumab increased FEV1 by $114 \mathrm{~mL}$ and $271 \mathrm{~mL}$ compared with placebo in the Step 4 and Step 5 populations, respectively. Similar improvements were observed at week 52, with FEV1 increases of $103 \mathrm{~mL}$ and $237 \mathrm{~mL}$ in the Step 4 and Step 5 populations, respectively. Reslizumab increased FEV 1 as early as the first study assessment, at week 4, and the FEV1 improvement was sustained throughout treatment (fig. 2b).

Analyses of FEV 1 by baseline therapy in the Step 4 subgroup demonstrated that reslizumab improved FEV1, regardless of the intensity of baseline ICS/LABA therapy. At week 16, reslizumab increased FEV1 by $101 \mathrm{~mL}$ (95\% CI 36-165) in the medium-dose ICS/LABA group and by $132 \mathrm{~mL}$ (95\% CI 46-219) in the high-dose ICS/LABA group. Data at week 52 were generally consistent with those at week 16, with increases of $96 \mathrm{~mL}$ (95\% CI 30-162) and $118 \mathrm{~mL}$ (95\% CI 35-201) in the medium-dose and high-dose ICS/LABA groups, respectively.

In Step 4 patients, mean forced vital capacity (FVC) increased between baseline and the end of treatment in both arms, with a larger increase in the reslizumab arm $(220 \mathrm{~mL}$, from $3.091 \mathrm{~L}$ to $3.320 \mathrm{~L})$ compared with the placebo arm $(117 \mathrm{~mL}$, from $2.965 \mathrm{~L}$ to $3.091 \mathrm{~L})$. In Step 5 patients mean FVC improved by $429 \mathrm{~mL}$ in the reslizumab arm (from $2.768 \mathrm{~L}$ to $3.197 \mathrm{~L}$ ) and by $111 \mathrm{~mL}$ in the placebo arm (from $2.964 \mathrm{~L}$ to $3.094 \mathrm{~L}$ ). Median FEV1/FVC ratio in Step 4 patients was $65.5 \%$ at baseline and $67.6 \%$ at the end of treatment in the reslizumab arm versus $65.9 \%$ (baseline) and $66.4 \%$ (end of treatment) in the placebo arm. 
a





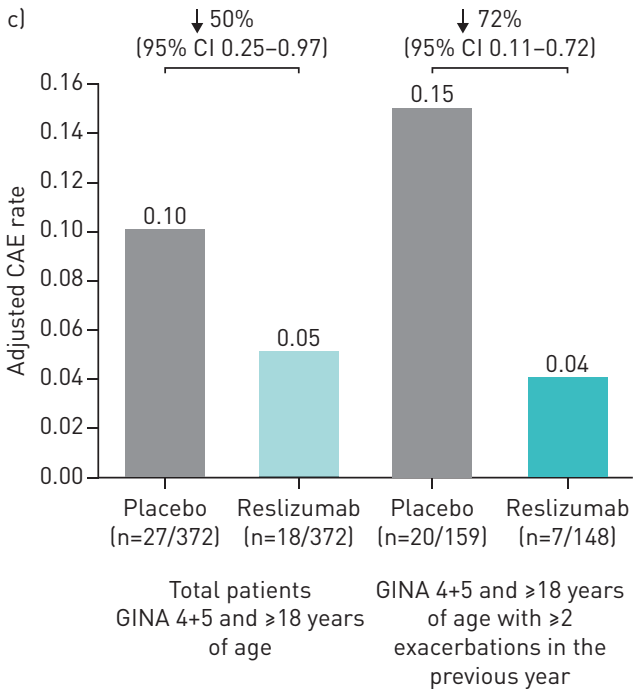

FIGURE 1 Effects of reslizumab on: (a) clinical asthma exacerbation (CAE) rates; (b) rates of clinical asthma exacerbation requiring oral corticosteroids (OCS); and (c) rates of CAEs requiring hospitalisation or an emergency room visit, in Global Initiative for Asthma (GINA) Step 4 and 5 patients.

In Step 5 patients median FEV1/FVC ratios were $62.2 \%$ (baseline) and $65.0 \%$ (end of treatment) in the reslizumab arm versus $61.2 \%$ (baseline) and $65.0 \%$ (end of treatment) in the placebo arm.

\section{Patient-reported outcomes \\ Control of symptoms}

Asthma control, as assessed using the ACQ-7 questionnaire, was improved with reslizumab in Step 4 and Step 5 patient groups (fig. 3a).

Compared with placebo, reslizumab improved asthma control, reducing the ACQ-7 scores by -0.333 (95\% CI $-0.438--0.227)$ and -0.192 points $(95 \%$ CI $-0.564--0.179)$ at week 16 and by -0.330 (95\% CI $-0.435--0.224)$ and -0.247 points $(95 \%$ CI $-0.679,0.136)$ at week 52 in the Step 4 and Step 5 groups, respectively (fig. 3a). Improved asthma control with reslizumab was demonstrated throughout therapy, from the week 4 assessment until the end of the study (fig. 3b).

Analyses of asthma control with reslizumab by Step 4 baseline therapy are shown in supplementary table S1.

Responder analyses were performed for ACQ-7-evaluable adult patients only, owing to the low number of adolescent patients. A higher proportion of those patients receiving reslizumab had a clinically meaningful improvement in ACQ-7 score (a decrease in score $\geqslant 0.5)[17,19]$ compared with placebo at week $16(66 \%$ versus $55 \%)$ and week 52 (80\% versus $61 \%)$. 


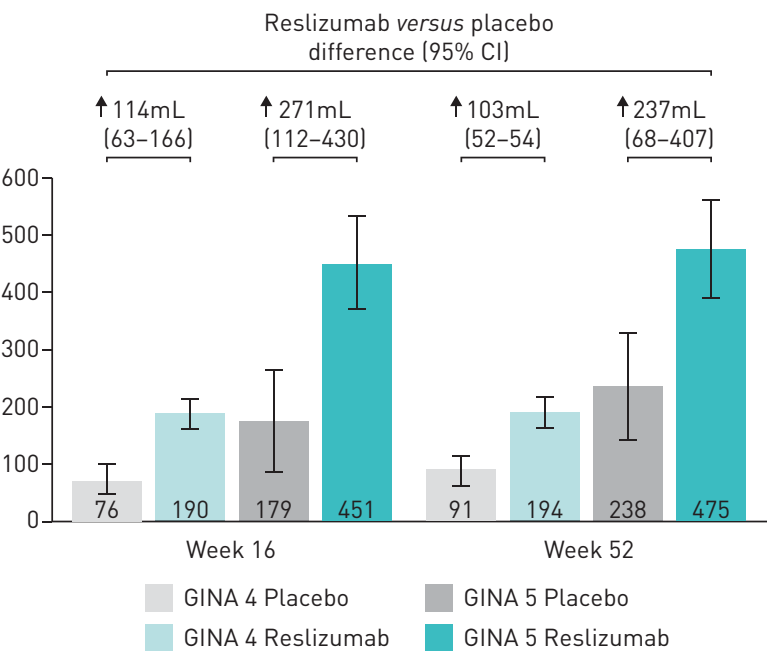

FIGURE 2 Effects of reslizumab on lung function (forced expiratory volume in $1 \mathrm{~s} ; \mathrm{FEV} 1$ ) in Global Initiative for Asthma (GINA) Step 4 and 5 patients. (a) Changes from baseline FEV 1 at week 16 and week 52 and (b) changes relative to placebo throughout the study. LS: least square.

b)

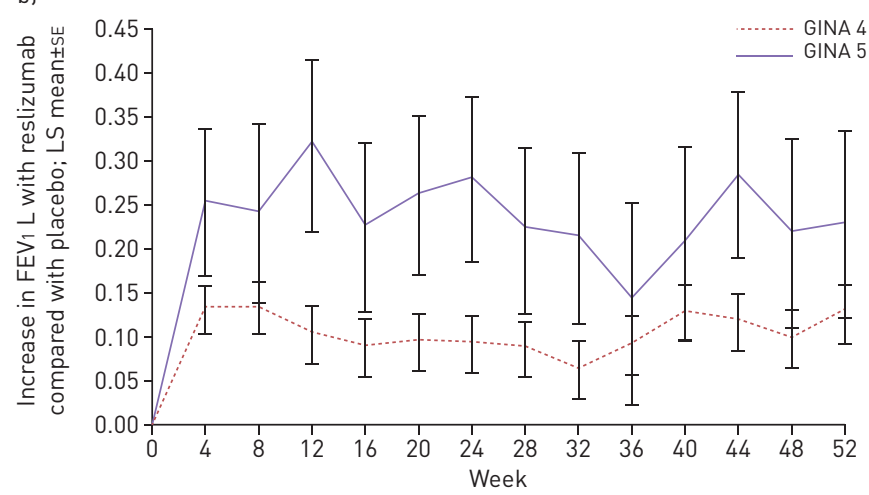

\section{Quality of life}

Compared with placebo, reslizumab improved QoL in Step 4 and Step 5 patients when assessed at weeks 16, 32 and 52 (fig. 4).

Analyses of AQLQ scores by baseline GINA Step 4 therapy are shown in supplementary table S2. Responder analyses were performed for adult patients only. Of the evaluable patients, a higher proportion of those receiving reslizumab had a clinically meaningful improvement in AQLQ score $(\geqslant 0.5$ increase in score) compared with placebo at week 16 (63\% versus 54\%) and week 52 (74\% versus 63\%).

\section{Discussion}

The results of this analysis highlight that intravenous reslizumab, given as a $3 \mathrm{mg} \cdot \mathrm{kg}^{-1}$ dose every 4 weeks, improves outcomes in patients with severe eosinophilic asthma in terms of exacerbations, lung function and patient-reported outcomes. These benefits can be seen in patients requiring either GINA Step 4 or Step 5 therapy. Patients requiring Step 5 therapy, by definition, have more severe asthma and are more likely to experience a CAE than patients at Step 4. In the previous publication, data were presented for the overall patient populations including Step 3, Step 4 and Step 5 patients. The data from our sub-analyses clearly show that, in adult patients with severe eosinophilic asthma, reslizumab reduces the CAE rate in Step 4 and Step 5 treatment groups, with the most pronounced reduction occurring in the Step 5 group.

In general, the magnitude of the improvements in CAE rate and FEV1 with reslizumab versus placebo was greater in the Step 5 group than the Step 4 group, which might be attributed to the severity of their disease and the potential room for improvement in patients requiring Step 5 treatment. The Step 5 patient population may represent the proposed T-helper-2-high asthma endotype that is characterised by severe asthma, with airway and systemic eosinophilia, responsiveness to glucocorticoids and inhibitors of type- 2 inflammation, such as IL-5 [20]. Such a population is likely to be highly responsive to immune-directed therapies that target regulators of eosinophil function.

In terms of exacerbations, not only did reslizumab reduce the rate of exacerbations in both groups, it also reduced the occurrence of the most severe exacerbations requiring healthcare utilisation. The use of a 

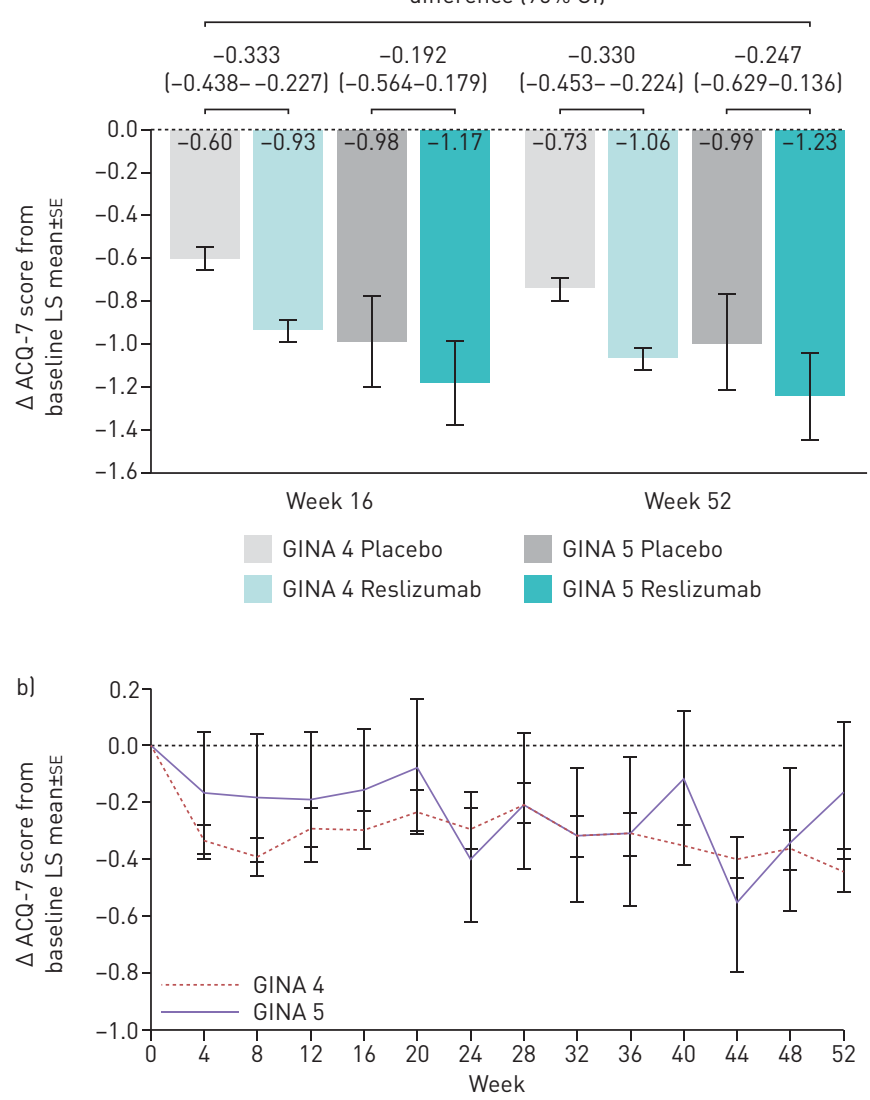

FIGURE 3 Effects of reslizumab on asthma control questionnaire-7 (ACQ-7) score in Global Initiative for Asthma (GINA) Step 4 and 5 patients. (a) Changes from baseline ACQ-7 score at week 16 and week 52 and (b) changes relative to placebo throughout the study. Increase in control is represented by a decrease in ACQ-7 score $[16,19]$. LS: least square.

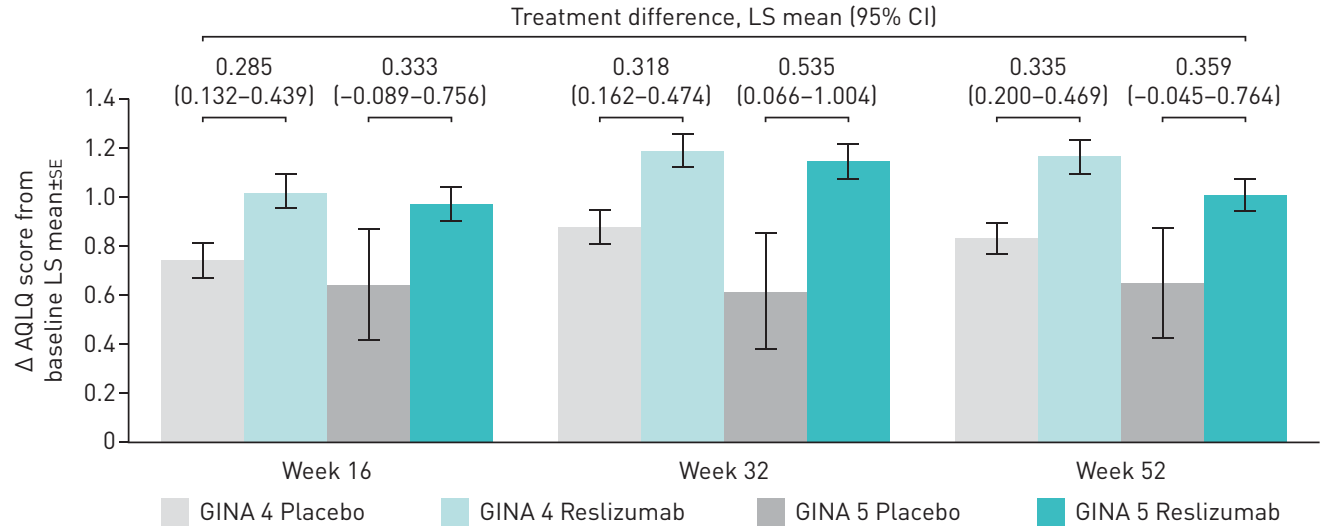

FIGURE 4 Effects of reslizumab on asthma quality of life questionnaire (AQLQ) score in Global Initiative for Asthma (GINA) Step 4 and 5 patients. Changes from baseline AQLQ score at week 16, week 32 and week 52 . Increased quality of life is represented by increased AQLQ score. The first post-baseline measurement for AQLQ was at week 16. LS: least square.

therapy that reduces the exposure to OCS and the need for hospitalisation/admission has the potential to decrease the burdens placed on patients with uncontrolled severe asthma and the emergency departments treating them.

Interestingly, the QoL benefits provided by reslizumab are comparable in Step 4 and Step 5 groups, despite the differences in CAE, FEV1 and ACQ endpoints in Step 4 and Step 5 groups. Approximately 40\% of 
patients in the study populations have no history of atopy and $42 \%$ and $66 \%$ in Step 4 and Step 5 groups, respectively, are not allergic (table 1). The improvements in QoL seen upon treatment with reslizumab may not be fully captured by the AQLQ.

Phase III studies of other antibodies targeting IL-5 or its receptor have also demonstrated reductions in exacerbation rates and improvements in lung function [21-23]. Treatment with the anti-IL-5 antibody mepolizumab subcutaneously or intravenously for 32 weeks resulted in a $47-53 \%$ reduction in the rate of asthma exacerbations compared with placebo in 576 patients with recurrent exacerbations and evidence of eosinophilic inflammation. The mean increase in FEV1 was also $98-100 \mathrm{~mL}$ greater in mepolizumab-treated patients [21]. Similarly, two Phase III trials of the anti-IL-5 receptor antibody benralizumab have reported comparable reductions in exacerbation rates and improvements in FEV1 after $48-56$ weeks' treatment every 4 or 8 weeks $[22,23]$. These data support the use of therapies targeting IL-5 stimulation in treatment of asthma in patients with elevated eosinophil levels, though differences in patient characteristics, eosinophil levels and trial design preclude direct comparison between trials. Also, efficacy of benralizumab and mepolizumab specifically in Step 4 and Step 5 patients is not reported in these studies. Overall, the data from our sub-analyses are consistent with those previously published for Phase III clinical studies of reslizumab and add to the body of evidence demonstrating the efficacy of reslizumab in patients with severe eosinophilic asthma [9-11]

Based on these data, we conclude that reslizumab reduces exacerbation rates and improves lung function and patient-reported outcomes in adult patients with eosinophilic asthma receiving therapy according to GINA Step 4 and 5.

\section{Acknowledgements}

This research was funded by Teva Branded Pharmaceutical Products R\&D. We thank the patients who participated in these two studies, the investigators, staff at all study sites and Hedley Coppock of Health Interactions, part of Nucleus Global, for writing support (funded by Teva Branded Pharmaceutical Products R\&D).

\section{References}

1 World Health Organization. Chronic respiratory diseases. www.who.int/respiratory/asthma/en/ Date last accessed: August 2016

2 Masoli M, Fabian D, Holt S, et al. The global burden of asthma: executive summary of the GINA Dissemination Committee report. Allergy 2004; 59: 469-478.

3 Global Initiative for Asthma (GINA). GINA report. Global Strategy for Asthma Management and Prevention, updated April 2015. ginasthma.org/wp-content/uploads/2016/01/GINA_Report_2015_Aug11-1.pdf Date last accessed: January 2016.

4 Chung KF, Wenzel SE, Brozek JL, et al. International ERS/ATS guidelines on definition, evaluation and treatment of severe asthma. Eur Respir J 2014; 43: 343-373.

5 Schleich FN, Chevremont A, Paulus V, et al. Importance of concomitant local and systemic eosinophilia in uncontrolled asthma. Eur Respir J 2014; 44: 97-108.

6 Price DB, Rigazio A, Campbell JD, et al. Blood eosinophil count and prospective annual asthma disease burden: a UK cohort study. Lancet Respir Med 2015; 3: 849-858.

$7 \quad$ Lambrecht BN, Hammad H. The immunology of asthma. Nat Immunol 2015; 16: 45-56.

8 de Groot JC, Ten Brinke A, Bel EH. Management of the patient with eosinophilic asthma: a new era begins. ERJ Open Res 2015; 1: 00024-2015.

9 Castro M, Zangrilli J, Wechsler ME, et al. Reslizumab for inadequately controlled asthma with elevated blood eosinophil counts: results from two multicentre, parallel, double-blind, randomised, placebo-controlled, phase 3 trials. Lancet Respir Med 2015; 3: 355-366.

10 Bjermer L, Lemiere C, Maspero J, et al. Reslizumab for inadequately controlled asthma with elevated blood eosinophil levels: a randomized phase 3 study. Chest 2016; 150: 789-798.

11 Corren J, Weinstein S, Janka L, et al. Phase 3 study of reslizumab in patients with poorly controlled asthma: effects across a broad range of eosinophil counts. Chest 2016; 150: 799-810.

12 Teva Respiratory, LLC. CINQAIR ${ }^{\bullet}$ (reslizumab) Prescribing Information. www.accessdata.fda.gov/drugsatfda_docs/ label/2016/761033lbl.pdf Date last accessed: July 2016.

13 Teva Pharmaceuticals Limited. CINQAERO (reslizumab) Summary of Product Characteristics. www.ema.europa. eu/docs/en_GB/document_library/EPAR_-_Product_Information/human/003912/WC500212250.pdf Date last accessed: August 2017.

14 Health Canada. Regulatory decision summary: CINQAIR (Control number 185873). https://hpr-rps.hres.ca/ reg-content/regulatory-decision-summary-detail.php?linkID=RDS00140 Date last accessed: August 2017.

15 Global Initiative for Asthma (GINA). 2016 Pocket Guide for Asthma Management and Prevention. http:// ginasthma.org/wp-content/uploads/2016/05/WMS-GINA-2016-main-Pocket-Guide.pdf Date last accessed: July 2016.

16 Qoltech. Asthma Control Questionnaire (ACQ). www.qoltech.co.uk/acq.html. Date last accessed January 2016.

17 Juniper EF, Guyatt GH, Willan A, et al. Determining a minimal important change in a disease-specific Quality of Life Questionnaire. J Clin Epidemiol 1994; 47: 81-87.

18 Juniper EF, O’Byrne PM, Guyatt GH, et al. Development and validation of a questionnaire to measure asthma control. Eur Respir J 1999; 14: 902-907.

19 Juniper EF, Svensson K, Mörk AC, et al. Measurement properties and interpretation of three shortened versions of the asthma control questionnaire. Respir Med 2005; 99: 553-558.

20 Fahy JV. Type 2 inflammation in asthma-present in most, absent in many. Nat Rev Immunol 2015; 15: 57-65. 
21 Ortega HG, Liu MC, Pavord ID, et al. Mepolizumab treatment in patients with severe eosinophilic asthma. $N$ Engl J Med 2014; 371: 1198-1207.

22 Bleecker ER, FitzGerald JM, Chanez P, et al. Efficacy and safety of benralizumab for patients with severe asthma uncontrolled with high-dosage inhaled corticosteroids and long-acting $\beta_{2}$-agonists (SIROCCO): a randomised, multicentre, placebo-controlled phase 3 trial. Lancet 2016; 29: 2115-2127.

23 FitzGerald JM, Bleecker ER, Nair P, et al. Benralizumab, an anti-interleukin-5 receptor $\alpha$ monoclonal antibody, as add-on treatment for patients with severe, uncontrolled, eosinophilic asthma (CALIMA): a randomised, double-blind, placebo-controlled phase 3 trial. Lancet 2016; 29: 2128-2141. 